\title{
Potentiometric Studies of Stability Constants and Speciation of Binary and Ternary Complexes of Metal (II) lons with Amino Acids and Thiobarbituric Acid
}

\author{
Kayode Taiwo Ishola ${ }^{1,}$, , Mary Adelaide Oladipo², Omobola Ajibike Odedokun ${ }^{1}$, \\ Oladapo Tunde Olanipekun ${ }^{1}$ \\ ${ }^{1}$ Department of Chemistry, Federal College of Education, (Special), Oyo, Nigeria \\ ${ }^{2}$ Department of Chemistry, Ladoke Akintola University of Technology, Ogbomoso, Nigeria
}

Email address:

Isholatk@gmail.com (K. T. Ishola), maoladipo@lautech.edu.ng (M. A. Oladipo), bolajibike@yahoo.com (O. A. Odedokun), ooladapotunde@gmail.com (O. T. Olanipekun)

${ }^{*}$ Corresponding author

\section{To cite this article:}

Kayode Taiwo Ishola, Mary Adelaid Oladipo e, Omobola Ajibike Odedokun, Oladapo Tunde Olanipekun. Potentiometric Studies of Stability Constants and Speciation of Binary and Ternary Complexes of Metal (II) Ions with Amino Acids and Thiobarbituric Acid. American Journal of Applied Chemistry. Vol. 8, No. 1, 2020, pp. 23-30. doi: 10.11648/j.ajac.20200801.14

Received: February 29, 2020; Accepted: March 19, 2020; Published: April 13, 2020

\begin{abstract}
Several chelating agents have been widely used as scavengers to transport metals to or away from vulnerable sites due to their ability to form stable complexes with different metal ions. Many of the chelating agents have been reported to be toxic, non-biodegradable and inflexible for the recovery of bound metal ions. The inherent drawbacks with these chelating agents necessitate a search for their replacement. Therefore, the extent of coordination of L-tyrosine, L-histidine (secondary ligands) and Thiobarbituric acid (primary ligand) with $\mathrm{Co}(\mathrm{II}), \mathrm{Cu}(\mathrm{II})$ and $\mathrm{Pb}(\mathrm{II})$ in an aqueous medium at $27^{\circ} \mathrm{C}$ and $35^{\circ} \mathrm{C}$ has been examined potentiometrically with ionic strength maintained by $0.02 \mathrm{M} \mathrm{NaNO}_{3}$. The potentiometric equilibrium measurements showed that the ligands formed binary and ternary complexes with the metal ions. Ternary complexes were formed by simultaneous mechanisms and they were found to be more stable than the corresponding binary complexes. The order of stability was found to increase with an increase in the covalent index of the metal ions and decrease with increase in temperature. Speciation diagram showed the variation in stability constants of the binary and ternary complexes as the function of $\mathrm{pH}$. The ligands exhibited high coordinating properties and could be used as metal scavengers for transportation of metals to or away from vulnerable sites. The binary metal complexes could be applied as a medium of transporting chemotherapeutic drugs to target sites or detoxifying poisonous substances which possesses donor atoms with chelating capability.
\end{abstract}

Keywords: Binary Complexes, Potentiometric, Speciation, Stability Constants, Ternary Complexes

\section{Introduction}

The advances in inorganic chemistry provide better opportunities to use coordination compounds and chelators in nutritional supplements, fertilizers, chemical analysis, as water softeners, commercial products such as shampoos and food preservatives, medicine, heavy metal detox, and industrial applications [1, 2]. Co-ordination compounds can be studied in two states: a solid state which entails synthesis, isolation and characterization of a pure compound, which can be subjected to a variety of tests, and a solution state which is based on equilibria in solution. The study of co-ordinate compounds in solution on the basis of equilibrium provides information on stability constants of the complexes which give detail of the complexation reactions of the metal ions, complex formation ability of the ligands and the activities of the complexes formed in a solution containing two or more component species in equilibrium.

The application of the transition metals in many industries have led to the contamination of air, soil and water which are now global problems that have become a growing threat to humanity. Many applied chelating agent in metal ions regulation have exhibited significant drawbacks. As a result of this, researchers have now focused on the study of 
interactions of biologically active ligands with various metal ions in solution in order to determine the possibility of using these bimolecular ligands in chelating therapy [4, 5]. Advancement in the field of bioinorganic chemistry has also led to increase in research on the complexes of $\mathrm{N}, \mathrm{O}, \mathrm{S}$-donor ligands since it has been recognized that many of these complexes may serve as models for biological and industrial applications $[6\}$. Amino acids, pyrimidine and their derivatives have been extensively studied as typical N, O, Sdonor ligands due to their coordinative capability [7] their pharmacological activity [8] and their uses in analytical chemistry as metal extracting agents [9]. However, there is a paucity of report on the coordinating abilities of some amino acids and Thiobarbituric acid with different metal ions. This study investigated binding abilities of L-histidine, Ltyrosine and Thiobarbituric acid with $\mathrm{Co}(\mathrm{II}), \mathrm{Cu}(\mathrm{II})$ and $\mathrm{Pb}(\mathrm{II})$ ions in forming binary and ternary complexes with a view of assessing their potential in transporting the metal ions to or away from vulnerable sites.

\section{Methodology}

\subsection{Materials}

The reagents and solvents used were of analytical grade. They include: Cobalt(II)nitrate hexahydrate, copper(II)nitrate hexahydrate lead(II)nitrate, sodium nitrate, nitric acid, sodium hydroxide, double distilled water, ethanol, oxalic acid, methyl orange indicator, EDTA, erichrome, L-histidine, Ltyrosine and thiobarbituric acid.

\subsection{Preparation of Solutions and Titration Procedure}

Solution of carbonate-free $0.13 \mathrm{M} \mathrm{NaOH}$ was prepared and standardized by oxalic acid. Solutions of metal ions $(0.002 \mathrm{M})$ were prepared from $\mathrm{Cu}\left(\mathrm{NO}_{3}\right)_{2} \cdot 6 \mathrm{H}_{2} \mathrm{O}, \mathrm{Co}\left(\mathrm{NO}_{3}\right)_{2} \cdot 6 \mathrm{H}_{2} \mathrm{O}$ and $\mathrm{Pb}\left(\mathrm{NO}_{3}\right)_{2} \cdot 6 \mathrm{H}_{2} \mathrm{O}$ and their concentrations were standardized with ethylenediaminetetraacetic acid. Nitric acid was standardized with a standard $\mathrm{NaOH}$ solution and the constant ionic strength was maintained with $0.02 \mathrm{M}$ sodium nitrate as an inert electrolyte.

$\mathrm{pH}$ measurements in the potentiometric titrations were carried out with a digital pH-meter (Mettler Teledo) equipped with a combined electrode. The $\mathrm{pH}$ meter was calibrated with standard buffer solutions of $\mathrm{pH} 4.00,7.00$ and 9.20 and all titrations were carried out within the slope of $>99 \%$. The errors arose mainly from the liquid junction, the alkaline and acidic errors of the glass electrode were corrected by using Van Uitert and Hass equation. The solution was maintained at temperatures of $27^{\circ} \mathrm{C} \pm 0.1$ and $35^{\circ} \mathrm{C} \pm 0.1$ respectively and the $\mathrm{pH}$ was recorded after the addition of $0.05 \mathrm{~cm}^{3}$ aliquots of carbonate-free $0.13 \mathrm{NaOH}$.

The following sets of solutions were prepared and total volume in each set was kept at $40.00 \mathrm{ml}$.

(a) $\mathrm{HNO}_{3}(0.01 \mathrm{M})$

(b) $\mathrm{HNO}_{3}(0.01)+$ L-tyrosine $(0.002 \mathrm{M})$

(c) $\mathrm{HNO}_{3}(0.01)+$ L-histidine $(0.002 \mathrm{M})$

(d) $\mathrm{HNO}_{3}(0.01)+$ Thiobarbituric acid $(0.002 \mathrm{M})$ (e) $\mathrm{HNO}_{3}(0.01)+$ L-tyrosine $(0.002 \mathrm{M})+\mathrm{M}(0.002 \mathrm{M})$

(f) $\mathrm{HNO}_{3}(0.01)+$ L-histidine $(0.002 \mathrm{M})+$ Metal $(0.002 \mathrm{M})$

(g) $\mathrm{HNO}_{3}(0.01)+$ Thiobarbituric acid $(0.002 \mathrm{M})$

(h) $\mathrm{HNO}_{3}(0.01)+$ Thiobarbituric acid $(0.002 \mathrm{M})+$ Metal $(0.002 \mathrm{M})$

(i) $\mathrm{HNO}_{3}(0.01)+$ Thiobarbituric acid $(0.002 \mathrm{M}+\mathrm{L}-$ tyrosine $(0.002 \mathrm{M})+\mathrm{M}(0.002 \mathrm{M})$

(j) $\mathrm{HNO}_{3}(0.01)+$ Thiobarbituric acid + L-histidine $(0.002 \mathrm{M})+\operatorname{Metal}(0.002 \mathrm{M})$

All the titrations were carried out in multiple in double distilled water. The obtained values of $\mathrm{pH}$ were plotted against volume of alkali added for the above sets of titration and titration curves were obtained using Origin 8 software. The equilibria existing in the solutions were examined from the curves. The protonation and the formation constants of the ligands and binary complexes respectively were determined using Point wise method by calculating the average number of metal ions associated with the ligand $\overline{n A}$ at different $\mathrm{pH}$ values, average number of ligand molecules attached per metal ion ( $\tilde{\mathrm{n}})$ and free ligand exponent $(\mathrm{pL})$. The formation constants of ternary complexes were determined using Ramamoorthy and Santapa method [10]. Distributions of species were obtained by Hyperquard Simulation and Speciation program.

\section{Results and Discussion}

Thiobarbituric acid has two dissociable NH groups while L-tyrosine and L-histidine has two dissociable and one protonable groups. The $\mathrm{pKa}$ values for the ligands were calculated from the curves by using Irving and Rossotti method, and compared with the literature values. During the titrations, no precipitate was formed indicating there is no tendency for formation of hydroxo complexes [10]. For the sake of briefness, the curves for the ligands, binary complexes and ternary complexes at $27^{\circ} \mathrm{C}$ and $35^{\circ} \mathrm{C}$ are presented in Figures 1 and 2 respectively.

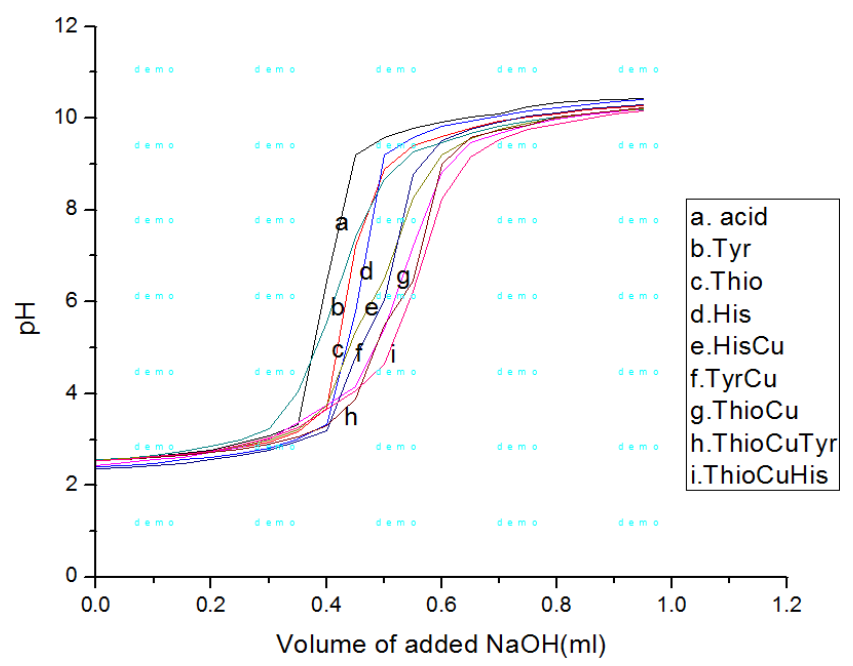

Figure 1. Representative titration curves for binary and ternary complexes of $\mathrm{Cu}(\mathrm{II})-\mathrm{A}$ and $\mathrm{M}$ (II)-Thio-L complexes at $27 \pm 0.1^{\circ} \mathrm{C}, \mu=0.020 \mathrm{M}\left(\mathrm{NaNO}_{3}\right) . A=L$ histidine, L-tyrosine and Thiobarbituric acid, $L=L$-histidine and L-tyrosine. 


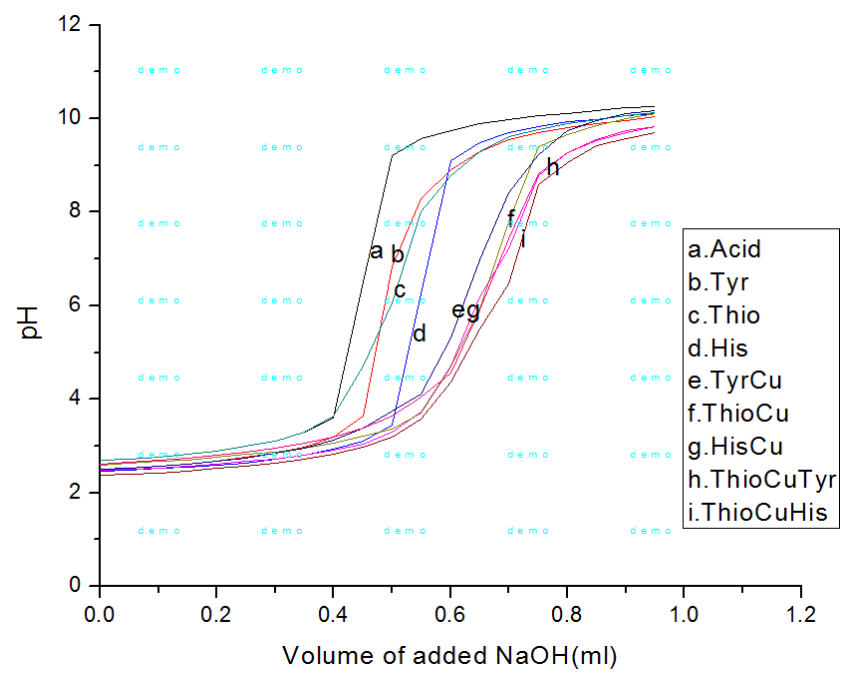

Figure 2. Representative titration curves for binary and ternary complexes of $\mathrm{Cu}(\mathrm{II})-\mathrm{A}$ and $\mathrm{M}(\mathrm{II})$-Thio- $L$ complexes at $35 \pm 0.1^{\circ} \mathrm{C}, \mu=0.020 \mathrm{M}\left(\mathrm{NaNO}_{3}\right)$. $A=L$-histidine, L-tyrosine and Thiobarbituric acid, $L=L$-histidine and $L$ tyrosine

It is observed from the Figures 1 and 2 above that there are divergences of curves $b, c$ and $d$ (ligands curves) from acid curve(a) which indicate deprotonation processes occurring from the ligands $[11,12]$. At $27^{\circ} \mathrm{C}$ and $35^{\circ} \mathrm{C}$, Thio curves show infection points at $\mathrm{pH}$ of 9.20 and 9.50 respectively; Tyr curves give inflection points at $\mathrm{pH}$ of 8.80 and 8.80 respectively while His shows inflection points at $\mathrm{pH}$ of 3.2 and 8.80 at $27^{\circ} \mathrm{C}$ and one inflection point at $\mathrm{pH}$ of 7.90 at $35^{\circ} \mathrm{C}$. The inflection points are attributed to dissociations of the protons from the ligands $[13,14]$. The shift of the ligands curves $\mathrm{a}, \mathrm{b}$ a and $\mathrm{c}$ in the figures to a lower $\mathrm{pH}$ region upon the addition of Metal(II) ions suggests the complex formation through displacement of proton(s) from the ligands $[11,15]$. In Figure 1, titration curves of binary complexes of Thio$\mathrm{Cu}(\mathrm{II})$, Tyr- $\mathrm{Cu}(\mathrm{II})$ and His- $\mathrm{Cu}(\mathrm{II})$ at $27^{\circ} \mathrm{C}$ show inflection points at $\mathrm{pH}$ of 4.15, 5.30 and 5.60 respectively. In Figure 2, infection points at $\mathrm{pH}$ of $4.80,6.20$ and 5.30 are shown in binary complexes of Thio- $\mathrm{Cu}(\mathrm{II}), \mathrm{Tyr}-\mathrm{Cu}$ (II) and His-Cu(II) respectively. The inflection points are attributed to the formation of $1: 1 \mathrm{Cu}(\mathrm{II}), 1: 1 \mathrm{Co}(\mathrm{II})$ and $1: 1 \mathrm{~Pb}(\mathrm{II})$ binary complexes of the ligands [16].

In Figure 1, curves $h$ and $i$ representing the titration curves of $1: 1: 1 \mathrm{Cu}(\mathrm{II})-\mathrm{Thio}-\mathrm{Tyro}$ and $1: 1: 1 \mathrm{Cu}(\mathrm{II})$-Thio-His species give inflection points at $\mathrm{pH}$ of 8.30 and 8.20 respectively; curves $\mathrm{h}$ and $\mathrm{i}$ representing the titration of $1: 1: 1 \mathrm{Cu}$ (II)-ThioTyro and 1:1:1Cu(II)-Thio-His show inflection points at $\mathrm{pH}$ of $8.70 \& 8.90$ respectively in Figure 2 . The formation of the ternary curves below the ligands curves and binary complexes curves, and the inflection points indicate the complexation of the metal ions with both ligands. Non superimposable nature of the ternary complexes curves with either of the simple binary curves suggests simultaneous complexation of the two ligands to the metal ions in the ternary complexes [17].

From the calculated average number of proton associated with the ligands $\overline{n A}$ at different $\mathrm{pH}$ values, association constants of the ligands, stability constants of the binary and ternary complexes obtained are presented in Tables 1, 2, 3, 4, 5 and 6.

Table 1. Proton-ligand stability constant of the ligands at $27^{\circ} \mathrm{C}$ and $35^{\circ} \mathrm{C}$ in water.

\begin{tabular}{|c|c|c|c|c|c|c|}
\hline \multirow{2}{*}{ Ligand } & \multicolumn{3}{|c|}{$27^{\circ} \mathrm{C}$} & \multicolumn{3}{|c|}{$35^{\circ} \mathrm{C}$} \\
\hline & $\operatorname{LogK}_{1}^{\mathrm{H}}$ & $\operatorname{LogK}_{2}^{\mathrm{H}}$ & $\log \beta$ & $\operatorname{LogK}_{1}^{\mathrm{H}}$ & $\log _{2}^{\mathrm{H}}$ & $\log \beta$ \\
\hline L-tyrosine & - & 10.9503 & 10.9503 & & 10.5449 & 10.5449 \\
\hline L-histidine & 3.3867 & 10.7160 & 14.1027 & - & 10.2068 & 10.2068 \\
\hline Thiobarbituric acid & - & 11.3567 & 11.3567 & - & 10.8750 & 10.8750 \\
\hline
\end{tabular}

Table 2. Stability constants of binary complexes in water medium at $27^{\circ} \mathrm{C}$ and $35^{\circ} \mathrm{C}$.

\begin{tabular}{|c|c|c|c|c|c|c|}
\hline \multirow{2}{*}{ Ligand } & \multicolumn{3}{|c|}{$27^{\circ} \mathrm{C}$} & \multicolumn{3}{|c|}{$35^{\circ} \mathrm{C}$} \\
\hline & $\log _{\mathrm{CuL}}^{\mathrm{Cu}}$ & $\operatorname{LogK}_{\mathrm{CoL}}^{\mathrm{CO}}$ & $\operatorname{LogK}_{\mathrm{PbL}}^{\mathrm{Pb}}$ & $\log _{\mathrm{CuL}}^{\mathrm{Cu}}$ & $\operatorname{LogK}_{\mathrm{CoL}}^{\mathrm{Co}}$ & $\operatorname{LogK}_{\mathrm{PbL}}^{\mathrm{Pb}}$ \\
\hline L-tyrosine & 6.3611 & 4.2222 & 6.9850 & 5.9363 & 4.1946 & 6.418 \\
\hline L-histidine & 7.3519 & 6.1681 & 5.6325 & 6.0837 & 6.0697 & 5.5922 \\
\hline Thiobarbituric acid & 7.4769 & 5.5542 & 6.6112 & 6.4067 & 5.1921 & 6.3355 \\
\hline
\end{tabular}

Table 3. Stability constants of Ternary complexes of Tyrosine and Thiobarbituric acid in water at $27^{\circ} \mathrm{C}(\mathrm{M}=\mathrm{Cu}(\mathrm{II})$, $\mathrm{Co}(\mathrm{II})$ and $\mathrm{Pb}(\mathrm{II}))$.

\begin{tabular}{|c|c|c|c|c|c|}
\hline Complex & $\operatorname{LogK}_{\mathrm{MAB}}^{\mathrm{M}}$ & $\operatorname{LogK}_{\mathrm{MA}}^{\mathrm{M}}$ & $\log K_{\mathrm{MAB}}^{\mathrm{MA}}$ & $\operatorname{LogK}_{\mathrm{MB}}^{\mathrm{M}}$ & $\Delta L$ LogK \\
\hline [CuThioTyr] & 15.2093 & 7.4769 & 7.7324 & 6.3611 & +1.3713 \\
\hline [CoThioTyr] & 14.4166 & 5.5542 & 8.8624 & 4.2232 & +4.6392 \\
\hline [PbThioTyr] & 15.4188 & 6.6112 & 8.8076 & 6.9830 & +1.8246 \\
\hline
\end{tabular}

Table 4. Stability constants of Ternary complexes of Tyrosine and Thiobarbituric acid in water at $35^{\circ} \mathrm{C}(\mathrm{M}=\mathrm{Cu}(\mathrm{II})$, Co(II) and Pb(II)).

\begin{tabular}{|c|c|c|c|c|c|}
\hline Complex & $\log K_{\mathrm{MAB}}^{\mathrm{M}}$ & $\operatorname{LogK}_{\mathrm{MA}}^{\mathrm{M}}$ & $\log K_{\mathrm{MAB}}^{\mathrm{MA}}$ & $\operatorname{LogK}_{\mathrm{MB}}^{\mathrm{M}}$ & $\Delta \operatorname{LogK}$ \\
\hline [CuThioTyr] & 14.1932 & 6.3122 & 7.8810 & 5.9363 & +1.9447 \\
\hline [CoThioTyr] & 13.5140 & 5.1921 & 8.3219 & 4.1946 & +4.1273 \\
\hline [PbThioTyr] & 15.3739 & 6.3353 & 9.0386 & 6.4180 & +2.6206 \\
\hline
\end{tabular}


Table 5. Stability constants of Ternary complexes in water at $27^{\circ} \mathrm{C}(\mathrm{M}=\mathrm{Cu}(\mathrm{II}), \mathrm{Co}(\mathrm{II})$ and $\mathrm{Pb}(\mathrm{II}))$.

\begin{tabular}{llllll}
\hline Complex & $\boldsymbol{L o g K}_{\mathrm{MAB}}^{\mathrm{M}}$ & $\boldsymbol{L o g K}_{\mathrm{MA}}^{\mathrm{M}}$ & $\boldsymbol{L o g K}_{\mathrm{MAB}}^{\mathrm{MA}}$ & $\boldsymbol{L o g K}_{\mathrm{MB}}^{\mathrm{M}}$ & $\Delta \boldsymbol{L o g K}$ \\
\hline [CuThioHis] & 15.5923 & 7.4769 & 8.1154 & 7.3519 & +0.5964 \\
{$[$ CoThioHis] } & 13.3877 & 5.5542 & 7.8335 & 6.1681 & +1.6654 \\
{$[$ PbThioHis] } & 14.2150 & 6.6112 & 7.6038 & 5.6325 & +1.9713 \\
\hline
\end{tabular}

Table 6. Stability constants of Ternary complexes in water at $35^{\circ} \mathrm{C}(\mathrm{M}=\mathrm{Cu}(\mathrm{II}), \mathrm{Co}(\mathrm{II})$ and $\mathrm{Pb}(\mathrm{II}))$.

\begin{tabular}{llllll}
\hline Complex & $\boldsymbol{L o g K}$ & $\operatorname{LogK}_{\mathrm{MAB}}^{\mathrm{M}}$ & $\boldsymbol{L o g K}_{\mathrm{MAB}}^{\mathrm{MA}}$ & $\boldsymbol{L o g K} \mathbf{M B}_{\mathrm{MB}}^{\mathrm{M}}$ & $\Delta \boldsymbol{L o g K}$ \\
\hline [CuThioHis] & 14.9340 & 6.3122 & 8.6218 & 5.9968 & +2.6250 \\
[CoThioHis] & 13.2481 & 5.1921 & 8.0560 & 6.0697 & +1.9863 \\
[PbThioHis] & 14.0145 & 6.3353 & 7.6792 & 5.5922 & +2.0870 \\
\hline
\end{tabular}

The mean $\log K_{2}^{H}$ values of 11.3567 and 10.8750 at $27^{\circ} \mathrm{C}$ and $35^{\circ} \mathrm{C}$ respectively observed in Thio as shown In Table 1 , are attributed to deprotonation at $\mathrm{N}_{3} \mathrm{H}$ groups present in the ligands [15]. The mean values $\log _{2}^{H}$ of 10.9503 and 10.5877 at $27^{\circ} \mathrm{C}$ and $37^{\circ} \mathrm{C}$ respectively of Tyr are ascribed to deprotonation at amino $\left(\mathrm{NH}_{2}\right)$ group of the ligand $[18,19]$. In His, two dissociation constants of $\log K_{1}^{H}$ of 3.3867 and $\log _{2}^{H}$ values of 10.7160 are obtained at $27^{\circ} \mathrm{C}$ which are attributed to deprotonation at $\mathrm{COOH}$ and Amino groups of the ligand respectively. While at $35^{\circ} \mathrm{C}$, only one deprotonation occurred with $\log K_{2}^{H}$ value of 10.2068 which is ascribed to deprotonation at amino group [20].

It is observed from Table 2 that His interacted with $\mathrm{Cu}(\mathrm{II})$, $\mathrm{Co}$ (II) and $\mathrm{Pb}$ (II) ions to form binary complexes with the stability constants in order of $L \operatorname{og} \mathrm{K}_{\mathrm{CuHis}}^{\mathrm{Cu}}>\log \mathrm{K}_{\mathrm{CoHis}}^{\mathrm{Co}}>\log \mathrm{K}_{\mathrm{PbHis}}^{\mathrm{Pb}}$. The increase in the order could be ascribed to ionization potential and ionic radius of the metal ions [21]. The stability of binary complexes of Tyr is in the order of $\operatorname{LogK}_{\mathrm{PbTyr}}^{\mathrm{Pb}}>\log \mathrm{K}_{\mathrm{CuTyr}}^{\mathrm{Cu}}>$ $\operatorname{LogK}_{\mathrm{CoTyr}}^{\mathrm{Co}}$ and the order could be attributed to covalent index of the metal ions. The higher the covalent index of a metal ion the more stable the complex formed by the metal $[22,23]$. While in binary complexes of Thiobarbituric acid, the stability constants were found in the order of $\operatorname{LogK}_{\mathrm{CuThio}}^{\mathrm{Cu}}>\log \mathrm{K}_{\mathrm{PbThio}}^{\mathrm{Pb}}>$ $L o g \mathrm{~K}_{\text {CoThio }}^{\mathrm{Co}}$. The extra stability exhibited by $\mathrm{Cu}$ (II)Thio complex could be assigned to the unique electronic configuration of $\mathrm{Cu}^{2+}$ and the Jahn-Teller effect [24]. At the two temperatures, all the ligands interact with the metal ions to give order of $\operatorname{LogK}_{\mathrm{CuThio}}^{\mathrm{Cu}}>$ $\log \mathrm{K}_{\mathrm{CuHis}}^{\mathrm{Cu}}>\log \mathrm{K}_{\mathrm{CuTyr}}^{\mathrm{Cu}}$ and the order is attributed to dissociation constants of the ligands and coordination of Thio ligand through $\mathrm{S}$ donor atom. The stability constants of the binary complexes of the order of $L o g \mathrm{~K}_{\mathrm{CoHis}}^{\mathrm{Co}}>\log \mathrm{K}_{\mathrm{CoThio}}^{\mathrm{Co}}>\log \mathrm{K}_{\mathrm{CoTyr}}^{\mathrm{Co}}$ is observed and attributed to coordination of the His through through nitrogen donor atoms of amino and imidazole group to form six membered ring [14], while with $\mathrm{Pb}$ (II), the order is $\operatorname{LogK}_{\mathrm{PbTyr}}^{\mathrm{Pb}}>$ $\log \mathrm{K}_{\mathrm{CoThio}}^{\mathrm{Co}}>\log \mathrm{K}_{\mathrm{PbHis}}^{\mathrm{Co}}$, this is attributed to high polarizing power of the ligands and covalent index of the metal ions $[22,25$, 26].

$\Delta \log \mathrm{K}$ was found to be positive in all the complexes in Tables $3 \& 4$ which indicates more stability of the ternary complexes than the corresponding binary complexes and the extra stability could be attributed to intramolecular aromaticring stacking and hydrogen bond [27]. The order of stability at the two temperatures is observed to be $\mathrm{Pb}$ (II) $>\mathrm{Cu}$ (II) $>\mathrm{Co}$ (II) and the extra stability exhibited by $\mathrm{Pb}(\mathrm{II})$ complexes could be attributed to higher covalent index and polarizability of $\mathrm{Pb}(\mathrm{II})$.

In Tables $5 \& 6, \Delta \log \mathrm{K}$ was also found to be positive in all the complexes indicating more stability of the complexes than their corresponding binary complexes. This stability is attributed to intramolecular aromatic-ring stacking and hydrogen bond. In the complexes, $\mathrm{Cu}$ (II) $>\mathrm{Pb}$ (II) $>\mathrm{Co}$ (II) order is found. The extra stability of $\mathrm{Cu}$ (II) complexes is attributed to the unique electronic configuration of $\mathrm{Cu}$ (II) ion and distorted geometry [28]. In all the complexes, stability constants decrease with increase in temperature.

Speciation of the binary and ternary complexes at different temperatures

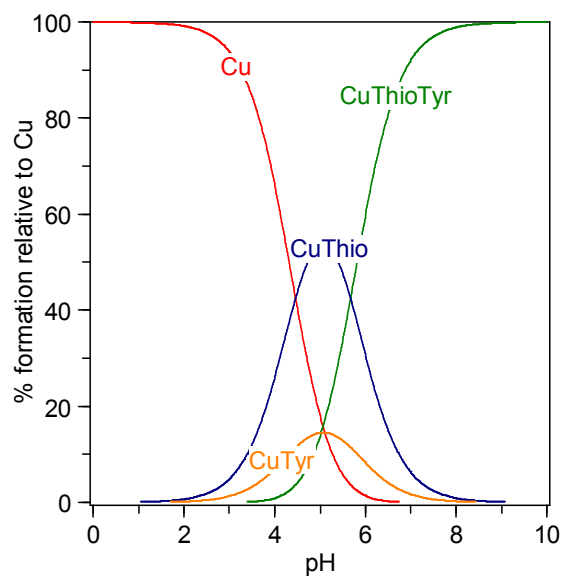

Figure 3. Distribution diagram of the species in the (1: 1: 1) Cu(II): Thio (A): $\operatorname{Tyr}(B)$ ternary system at $27^{\circ} \mathrm{C}$.

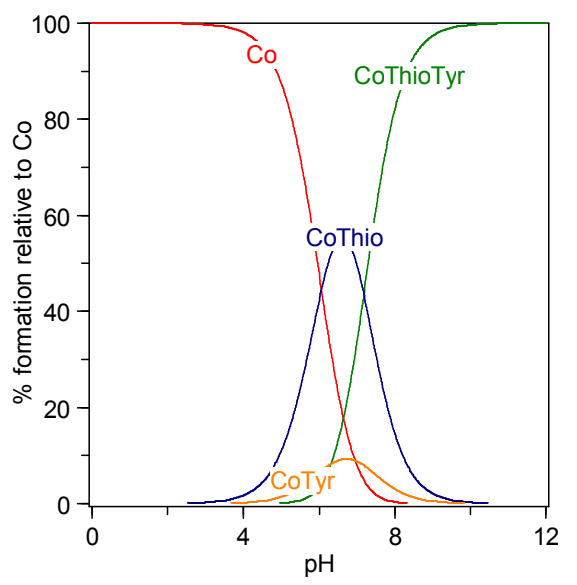

Figure 4. Distribution diagram of the species in the (1:1:1) Co(II): Thio (A): $\operatorname{Tyr}(B)$ ternary system at $27^{\circ} \mathrm{C}$. 


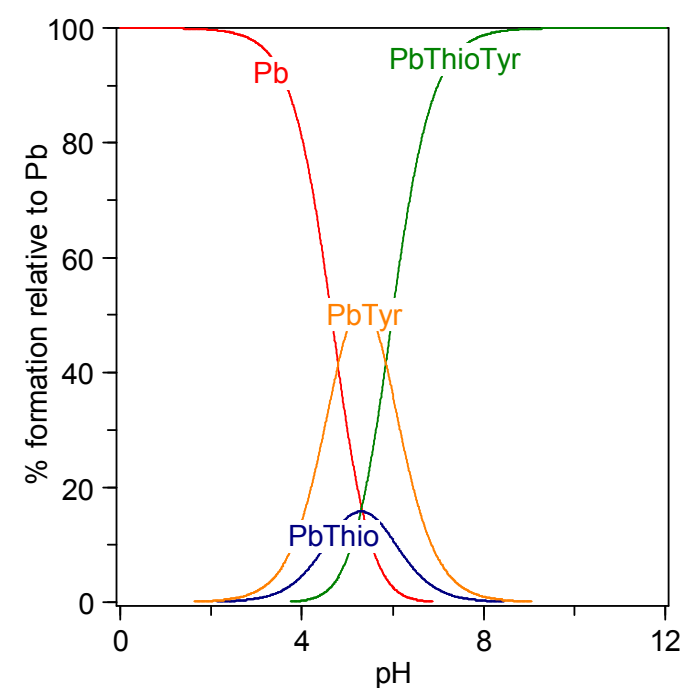

Figure 5. Distribution diagram of the species in the (1:1:1) Pb(II): Thio (A): $T y r(B)$ ternary system at $27^{\circ} \mathrm{C}$.

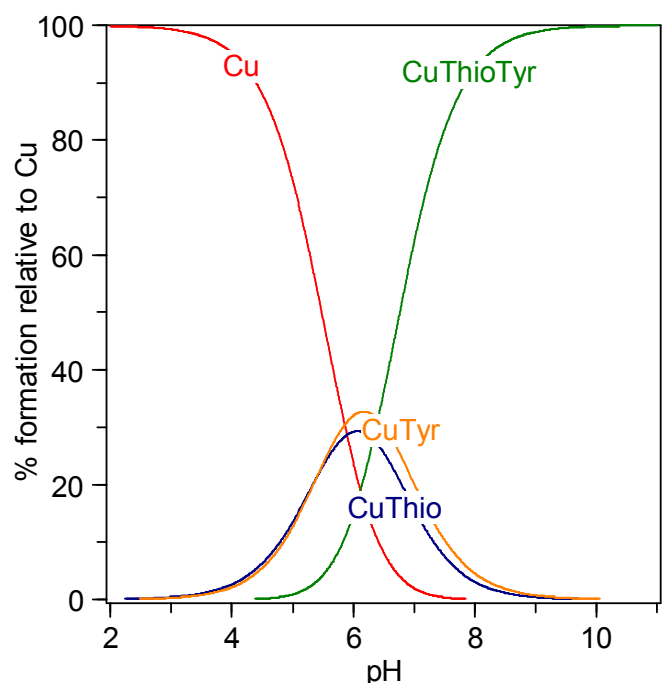

Figure 6. Distribution diagram of the species in the (1:1:1) Cu(II): Thio (A): Tyr (B) ternary system at $35^{\circ} \mathrm{C}$.

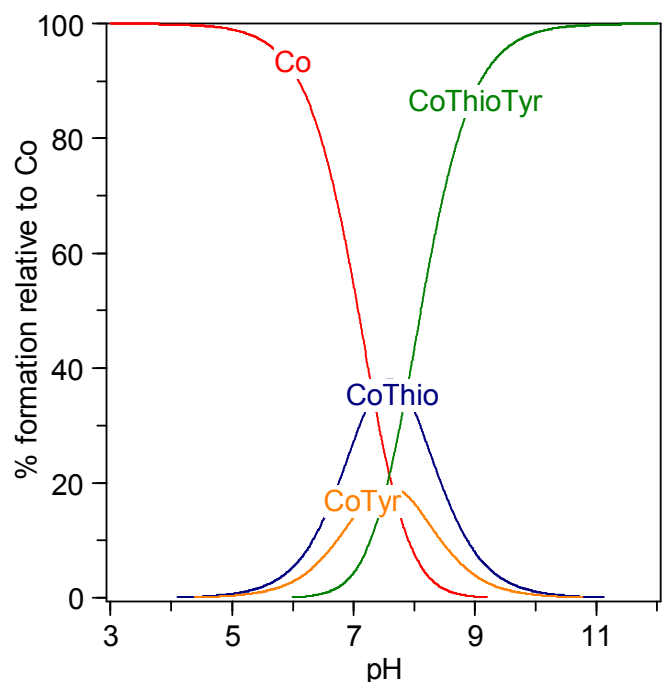

Figure 7. Distribution diagram of the species in the (1:1:1) Co(II): Thio (A): Tyr (B) ternary system at $35^{\circ} \mathrm{C}$.

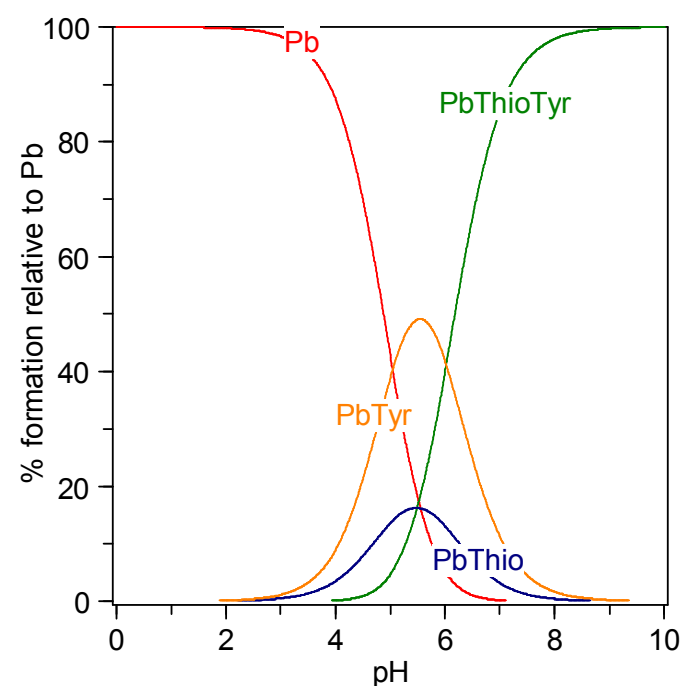

Figure 8. Distribution diagram of the species in the (1:1:1) Pb(II): Thio (A): $\operatorname{Tyr}(B)$ ternary system at $35^{\circ} \mathrm{C}$.

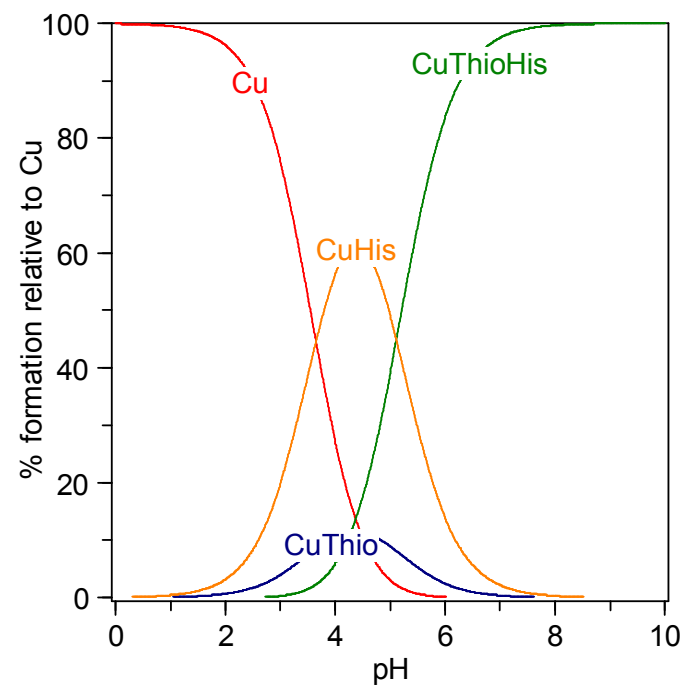

Figure 9. Distribution diagram of the species in the (1:1:1) Cu(II): Thio (A): His (B) ternary system at $27^{\circ} \mathrm{C}$.

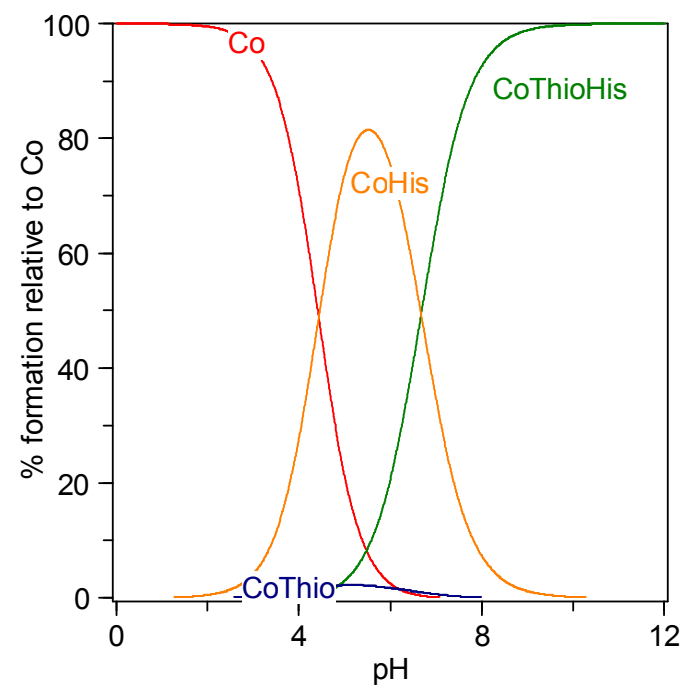

Figure 10. Distribution diagram of the species in the (1:1:1) Co(II): Thio (A): His (B) ternary system at $27^{\circ} \mathrm{C}$. 


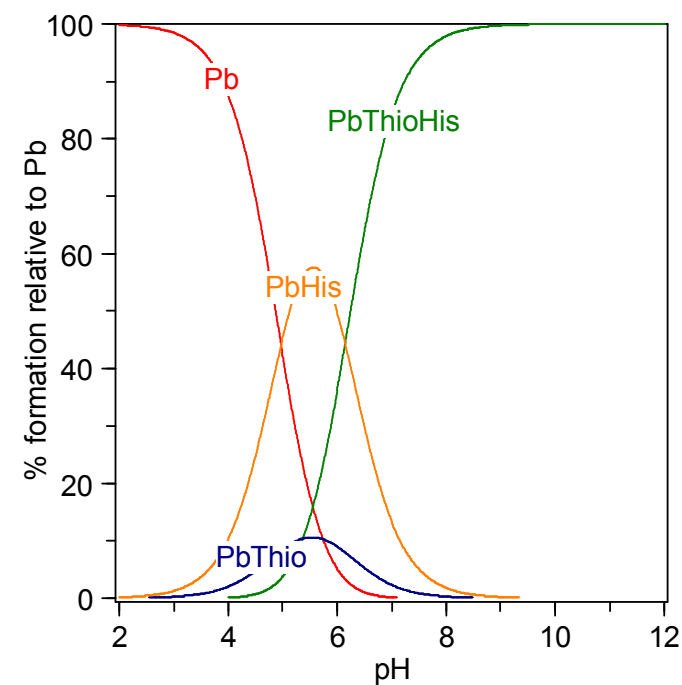

Figure 11. Distribution diagram of the species in the (1:1:1) Pb(II): Thio (A): His (B) ternary system at $27^{\circ} \mathrm{C}$.

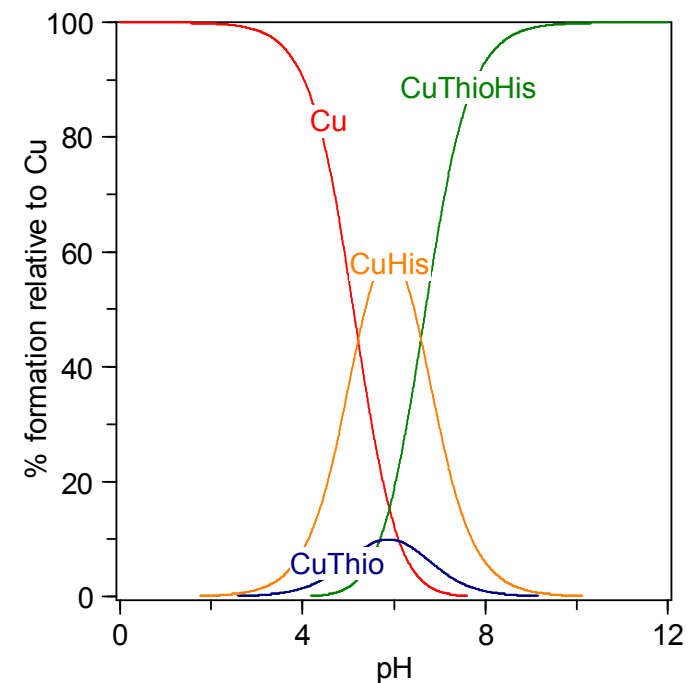

Figure 12. Distribution diagram of the species in the (1:1:1) Cu(II): Thio (A): His (B) ternary system at $35^{\circ} \mathrm{C}$.

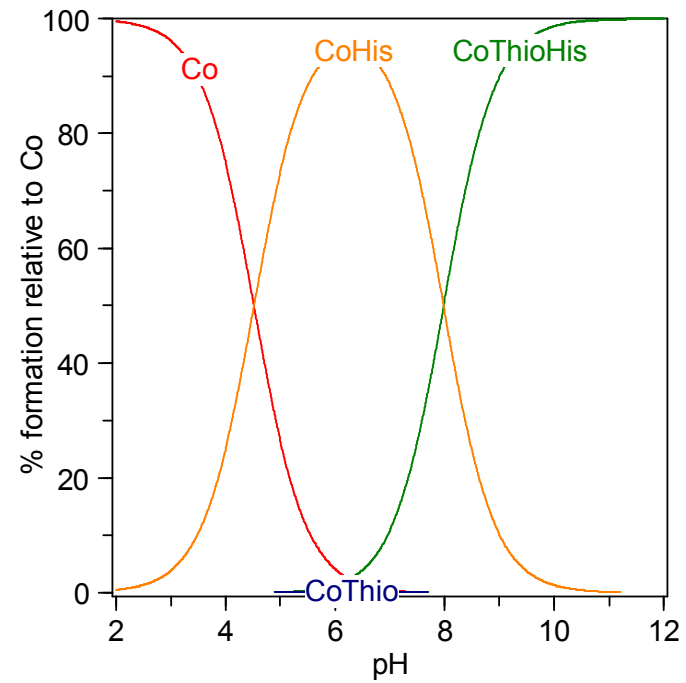

Figure 13. Distribution diagram of the species in the (1:1:1) Co(II): Thio (A): His (B) ternary system at $35^{\circ} \mathrm{C}$.

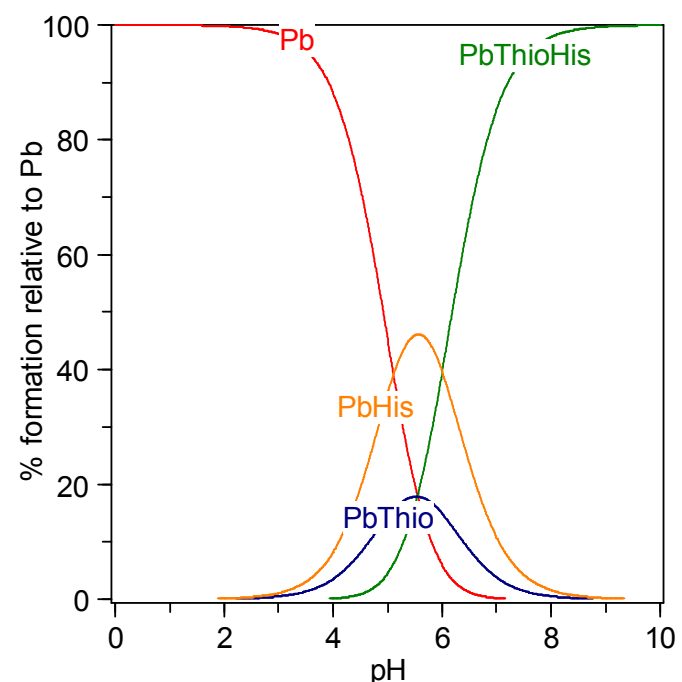

Figure 14. Distribution diagram of the species in the (1:1:1) Pb(II): Thio (A): His (B) ternary system at $35^{\circ} \mathrm{C}$.

Distribution diagrams of all the binary and ternary systems of $\mathrm{Co}(\mathrm{II}), \mathrm{Cu}(\mathrm{II})$ and $\mathrm{Pb}(\mathrm{II})$ were drawn by the Hyss computer program. The distributions of all the types of binary and ternary systems as a function of $\mathrm{pH}$ are given in Figures 3-14.

In the aqueous solution at $27^{\circ} \mathrm{C}, \mathrm{Cu}(\mathrm{II}) \mathrm{Tyr}$ and $\mathrm{Cu}(\mathrm{II}) \mathrm{Thio}$ binary complexes reached maximum levels (14\%) and (54\%) at $\mathrm{pH}$ of 5.0 and 5.2 respectively. The complexes began to dissociate at the $\mathrm{pH}$ and disappeared completely at $\mathrm{pH}$ of 8.0 and 9.0 respectively. Ternary complex of $\mathrm{Cu}(\mathrm{II}) \mathrm{ThioTyr}$ began to form at $\mathrm{pH}$ of 3.6 and reached its maximum level $(97 \%)$ at $\mathrm{pH}$ of 7.6 as shown in Figure 3. In figure 4, $\mathrm{Co}(\mathrm{II}) \mathrm{Tyr}$ and $\mathrm{Co}(\mathrm{II}) \mathrm{Thio}$ binary complexes reached their peaks $(10 \%)$ and $(55 \%)$ at $\mathrm{pH}$ of 6.7 and 6.6 respectively. The complexes began to dissociate at the $\mathrm{pH}$ and disappeared completely at $\mathrm{pH}$ of 9.5 and 10.0 respectively. Ternary complex of Co(II)ThioTyr came to an existence at $\mathrm{pH}$ of 5.0 and reached maximum level (97) at $\mathrm{pH}$ of 9.0. It is revealed in figure 5 that $\mathrm{Pb}(\mathrm{II}) \mathrm{Tyr}$ and $\mathrm{Pb}(\mathrm{II})$ Thio binary complexes got to maximum levels $(52 \%)$ and $(16 \%)$ at $\mathrm{pH}$ of 5.4 and 5.3 respectively. The dissociation of the complexes occurred as $\mathrm{pH}$ increased and $\mathrm{Pb}$ (II)Tyr and $\mathrm{Pb}$ (II)Thio disappeared completely at $\mathrm{pH}$ of 9.0 and 8.0 respectively. $\mathrm{Pb}$ (II)ThioTyr ternary complex began to form at $\mathrm{pH}$ of 3.8 and reached maximum level (97) at $\mathrm{pH}$ of 9.7.

At $35^{\circ} \mathrm{C}$ as depicted in Figure 6, $\mathrm{Cu}(\mathrm{II}) \mathrm{Tyr}$ and $\mathrm{Cu}(\mathrm{II})$ Thio binary complexes reached maximum levels $(33 \%)$ and $(30 \%)$ at $\mathrm{pH}$ of 6.0 and 6.3 respectively. The complexes began to dissociate at the $\mathrm{pH}$ and disappeared completely at $\mathrm{pH}$ of 10.0 and 9.6 respectively. Ternary complex of $\mathrm{Cu}(\mathrm{II}) \mathrm{ThioTyr}$ began to form at $\mathrm{pH}$ of 4.4 and reached its maximum level (97\%) at $\mathrm{pH}$ of 8.42 . The binary complexes of Co(II)Tyr and $\mathrm{Co}$ (II)Thio got to the maximum levels $(20 \%)$ and $(38 \%)$ respectively at $\mathrm{pH}$ of 7.6 as shown in Figure 7. They began to dissociate and disappeared at $\mathrm{pH}$ of 10.56 and 10.98 respectively. Co(II)ThioTyr Ternary complex began to form at $\mathrm{pH}$ of 4.4 and reached maximum level (98) at $\mathrm{pH}$ of 9.8 . Figure 8 shows that binary complex of $\mathrm{Pb}(\mathrm{II}) \mathrm{Tyr}$ and 
$\mathrm{Pb}(\mathrm{II})$ Thio reached maximum levels $(47 \%)$ and $(10 \%)$ at $\mathrm{pH}$ of 5.6 and 5.7 respectively. The complexes began to dissociate as the $\mathrm{pH}$ increased and disappeared at $\mathrm{pH}$ of 9.4 and 8.7 respectively. Ternary complex came to an existence at $\mathrm{pH}$ of 5.0 and reached maximum level $(97 \%)$ at $\mathrm{pH}$ of 7.9 .

The binary complexes of $\mathrm{Cu}(\mathrm{II}) \mathrm{His}$ and $\mathrm{Cu}(\mathrm{II})$ Thio formed from interactions of L-histidine and Thiobarbituric acid with $\mathrm{Cu}(\mathrm{II})$ in aqueous solution at $27^{\circ} \mathrm{C}$ reached maximum levels $(60 \%)$ and $(12 \%)$ at $\mathrm{pH}$ of 5.1 and 5.2 respectively. The complexes began to dissociate with increase in $\mathrm{pH}$ and disappeared completely at $\mathrm{pH}$ of 8.6 and 7.8 respectively. Ternary complex of $\mathrm{Cu}$ (II)ThioHis began to form at $\mathrm{pH}$ of 3.5 and reached maximum level(96\%) at $\mathrm{pH}$ of 7.6 as shown in Figure 9. In Figure 10, $\mathrm{Co}$ (II)His and $\mathrm{Co}$ (II)Thio reached maximum levels $(85 \%)$ and $(2 \%)$ at $\mathrm{pH}$ of 5.7 and 5.5 respectively. The complexes began to dissociate at $\mathrm{pH}$ above their optimum $\mathrm{pH}$ and completely disappeared at $\mathrm{pH}$ of 10 and 8 respectively. $\mathrm{Co}(\mathrm{II})$ ThioHis ternary complex came to an existence at $\mathrm{pH}$ of 4.0 and reached maximum level (96\%) at $\mathrm{pH}$ of $8.7 \mathrm{~Pb}(\mathrm{II}) \mathrm{His}$ and $\mathrm{Pb}(\mathrm{II})$ Thio binary complexes reached maximum levels $(58 \%)$ and $(10 \%)$ at $\mathrm{pH}$ of 5.6 respectively as depicted in Figure 11 . They began to dissociate as $\mathrm{pH}$ increased and disappeared at $\mathrm{pH}$ of 9.0 and 8.0 respectively. Ternary complex of $\mathrm{Pb}$ (II)ThioHis began to form at $\mathrm{pH}$ of 4.0 and reached maximum level (97\%) at $\mathrm{pH}$ of 8.0.

At $35^{\circ} \mathrm{C}$ in Figure 12 , binary complexes $\mathrm{Cu}(\mathrm{II}) \mathrm{His}$ and $\mathrm{Cu}(\mathrm{II}) \mathrm{Thio}$ reached maximum levels $(59 \%)$ and $(10 \%)$ respectively at $\mathrm{pH}$ of 6.0 . They began to dissociate and completely disappeared at $\mathrm{pH}$ of 10.0 and 9.0 respectively. The ternary complex of $\mathrm{Cu}$ (II)ThioHis came to an existence at $\mathrm{pH}$ of 4.0 and reached maximum level $(96 \%)$ at $\mathrm{pH}$ of 8.4 . It is shown in Figure 13 that $\mathrm{Co}(\mathrm{II}) \mathrm{His}$ dominated the reaction in this aqueous solution and reached maximum level $(95 \%)$ at $\mathrm{pH}$ of 6.0 and began to dissociate and disappeared at $\mathrm{pH}$ of 10.0 . $\mathrm{Co}(\mathrm{II})$ ThioHis ternary complex came to an existence at $\mathrm{pH}$ of 4.6 and reached maximum level (96\%) at $\mathrm{pH}$ of 9.0. In Figure 14, $\mathrm{Pb}$ (II)His and $\mathrm{Pb}$ (II)Thio binary complexes reached maximum levels $(43 \%)$ and $(20 \%)$ at $\mathrm{pH}$ of 5.6 and 5.4 respectively. They began to dissociate as $\mathrm{pH}$ increases and disappeared at $\mathrm{pH}$ of 9.0 and 8.4 respectively. Ternary complex of $\mathrm{Pb}(\mathrm{II}) \mathrm{ThioHis}$ began to form at $\mathrm{pH}$ of 3.5 and reached maximum level $(9 \%)$ at $\mathrm{pH}$ of 7.8 .

\section{Conclusion}

The study of stability constants of coordination compounds in solution provides comprehensive knowledge on the complexation reactions of metals, complex formation ability of the ligands and the activities of the complexes formed which serves as a tool for determination of metalligand reactions in water and biological system for potential applications. It is revealed that the stability constants increase when metal ion with high covalent index interacts with a ligand that possesses high polarizability. All the ternary complexes were observed to be more stable than the corresponding binary complexes and the stability of the ternary complexes follows the order of $\mathrm{Pb}$ (II) $>\mathrm{Cu}$ (II) $>\mathrm{Co}$ (II). The complexes' stability constants decrease with increase in temperature. All the ligands formed more stable binary complexes with the metal ions with within $\mathrm{pH}$ of 4.0-6.5 and above this $\mathrm{pH}$ region, the binary complexes dissociated thereby, at the $\mathrm{pH}$ above 4.0-6.5 the complexes can be separated to the metal ions and the chelators could be reused. The mixed-ligand formed stable ternary complexes within $\mathrm{pH}$ of 7-10 and above this $\mathrm{pH}$; the complexes could be dissociated to the metal ions and the chelators. The ligands could be used as metal scavengers for transportation of the metal ions to or away from target sites and as an antidote in combating metal poisoning within the stipulated $\mathrm{pH}$ region. The binary complexes could also be applied as a medium of transporting chemotherapeutic drugs to target sites or detoxifying poisonous substances which possesses donor atoms with chelating capability.

\section{References}

[1] Swaddle, T. W. Inorganic Chemistry: An Industrial and Environmental Perspective. Chem. Educ. 1997, 74, 12, 13-99

[2] Hernandez-Gil, J., Perello, L., Ortiz, R., Alzuet, G., GonzalezAlvarez, M. \& Liu-Gonzalez, M. Synthesis, structure and biological properties of several binary and ternary complexes of copper(II) with ciprofloxacin and 1, 10 phenanthroline. Polyhedron, 2009, 28, 138-144.

[3] Masoud, M. S., El-Merghany, A., Abd El-Kaway, M. Y. Synthesis and physico-chemical properties of biologically active purine complexes. Syn. React. Inorg. Met. Org. Nano Met. Chem., 2009, 39, 537-553.

[4] Maslowska, J. \& Owczarek, A. Potentiometric studies on mixed complexes of alkaline earth group metals with ascorbic and tartaric acid. Polish Journal of Chemistry, 1988, 62, 75-82.

[5] Kleszczewska, E. The spectrophotometry determination of chelate complex: L-ascorbic acid with cuprum (II) and mercury (II) in alkaline solution. Polish Journal of Environmental Studies, 1999, 8 (5), 313 - 318.

[6] Hughes, M. N. (1981). The Inorganic Chemistry of Biological Processes, 2nd edn., New York: John Wiley \& Sons.

[7] Liang, Y. M., Liu, C. M., Ma, Y. X. \& Li. Q. S. Formylferrocene 5- phenyloxazole-2 carbonylhydrazone bivalent transition metal complexes. Transition Met. Chem.,. 1998, 23, 97-99.

[8] Haran, R., Gairin, J. \& Commenges, G. Gallium-71, carbon13 and hydrogen-1NMR studies of the interactions of pyridoxal 5_-phosphate isonicotinyl hydrazone with gallium in aqueous solution. Inorg. Chim. Acta., 1980, 46, 63-67.

[9] Parashar, K., Sharma, R. C., Kumar, A. \& Mohan G. Stability studies in relation to IR data of some schiff base complexes of transition metals and their biological and pharmacological studies. Inorg. Chim. Acta., 1988, 151, 201-208.

[10] Shailendrasingh, V. T., Mazahar, F. \& Naikwadeb, S. D. study of binary complexes of transition metal ions and lanthanide metal ions with adenosine drug in mixed solvent system, Acta chim. pharm. Indica, 2013, 3 (1), 35-39. 
[11] Sumer, D. T., Devidas, T. M., Kamlesh, P. M., Rajesh, D. D. \& Mangesh, S. T. Metal ligand stability constants of Th(III), $\mathrm{Sm}(\mathrm{III}), \mathrm{Nd}(\mathrm{III})$ and $\mathrm{Pr}(\mathrm{III})$ metalion complexes with 2 mercapto-4-substituted phenyl-6-substituted phenyl pyrimidines at $0.1 \mathrm{M}$ ionic strength $\mathrm{pH}$ metrically, Der Pharma Chemica, 2011, 3 (6), 382-389.

[12] Jeyaprakash, D., Paramasivam, S., Thirugnanasamy, E., Sutha, S. \& Saravanan, R. Complexation Equilibria and Coordination Aspect of $\mathrm{Zn}$ (II) Complexes Contain 2 Aminobenzamide and some Bioactive Amino acid Mixed Ligands $\mathrm{pH}-$ metric, Spectroscopic and Thermodynamic Studies, Acta Chim. Slov., 2014, 61, 803-812.

[13] Sangita, S., Dipika, D. \& Madhurjya, N. A study of the formation constants of ternary and quaternary complexes of some bivalent transition metals, Journal of Serbian Chemical Society, 2010, 75 (1), 75-82.

[14] Ammar, R. A., Al-mutiri, R. A. \& Abdalla, M A. Equilibrium study of the mixedcomplexes of copper(II) with adenine and amino acids in aqueous solution. Journal of solution chemistry, 2010, 39, 727-737.

[15] Naciye, T. \& Suat, A. M. Complex Formation of Nickel(II) and Copper(II) with Barbituric Acid, International Journal of Analytical chemistry, 2014, 1-5.

[16] Bhattacharya, M., Iqbal S. A. \& Malik S. Studies on Furosemide Salicylaldehyde Schiff Base Complex with Copper(II) and Zinc(II). Asian journal of chemistry, 2006, 18, $1,715-717$.

[17] Abdulbaset, A. Z., Mazahar, F. B. \& Janrao, D. M. Study of stability constant of biological active molecules (drug) using potentiometric titration technique, Journal of Chemical, Biological and Physical Sciences, 2011, 2 (1), 67-8.

[18] Siham A. L. \& Reda, A. A. Mixed-ligand complex formation of cu(ii) with 1,2-diphenylethylenediamine as primary ligan and amino acids as secondary ligands. Int. J. electrochem. sci., 2012, 7, 7699-7711.

[19] Jahangir, M. A., Ullah, M. R. \& Mousume, A. Determination of stability constant of mixedn ligand complexes of $\mathrm{Ni}(\mathrm{II})$ and $\mathrm{Cu}$ (II) metal ions with Diethylenetriamine (DET) and
Ethylenediamine(en), Glycine (gly), alpha-Alanine (alpha-ala), Phenylalanine (ph-ala). Oxalic acid (ox), Tyrosine (tyr), Journal of Ultra Scientist of Physical sciences, 2018, 30 (2), $12-1$.

[20] Verma, S., Singh, D., Kumar, R., Shukla, B. K. \& Krishna, V. Equilibrium study and stability constants of mixed Ligand complexes of Biomolecules and Amino acids with Metal ions by Potentiometric method. Research Journal of Chemical Sciences, 2015, 5 (3), 42-48.

[21] Farooque, B. A., Patel, S. K. \& Quddri, S. H. A potentiometric study of stability of metal ion complexes with bidentate ligand. International Journal of Chemical Science, 2009, 7 (2), 10331038 .

[22] Nieboer, E. \& Richardson, D. H. S. The replacement of the nondescript term 'heavy metals' by a biologically and chemically significant classification of metal ions, Environmental Pollution Series B, Chemical and Physical, 1980, 1 (1): 3-26.

[23] Oladipo, M. A., Ishola, K. T. \& Ajayeoba, T. A. Investigation of Extent of Interaction of Thiobarbituric Acid and Two Selected Amino Acids with Three Divalent Metal Ions in Aqueous-organic Medium at Different Temperatures. Current Journal of Applied Science and Technology, 2019, 36 (3), 1-8.

[24] Shriver, D. F. \& Atkins, P. W. Inorganic chemistry (3rd ed.) 1999. Oxford: University press.

[25] Salvatore, M., Andrea, A., Arcangelo, M., Angelo, V. Electronic and vibrational polarizabilities of the twenty naturally occurring amino acids. Biophysical Chemistry, Elsevier, 2007, 132 (2-3), 139-146

[26] Marcel, S., Jaap G. S., \& Piet T. V. Polarizabilities of amino acid residues, Journal of Computational Methods in Sciences and Engineering, 2004, 4, 419-425.

[27] Usama, E., Kenawy, I. M. Usama, E., Kenawy, I. M. \& Abu, E. Y. G. Synthesis, thermal and spectral studies of first-row transition metal complexes with Girard-T reagent-based ligand Journal of Molecular Structure, 2007, 871 (3), 14-23.

[28] Haider, S. Z. (1994). Introduction to modem inorganic chemistry. Dhaka, Bangladesh: Frieends International. 